\title{
High resolution transmission electron microscope study on polyacrylonitrile /carbon nanotube based carbon fibers and the effect of structure development on the thermal and electrical conductivities
}

\author{
Bradley A. Newcomb ${ }^{1}$, Lucille A. Giannuzzi ${ }^{2}$, Kevin M. Lyons ${ }^{1}$, Prabhakar Gulgunje ${ }^{1}$, Kishor \\ Gupta $^{1}$, Yaodong Liu ${ }^{1}$, Manjeshwar Kamath ${ }^{1}$, Kenneth McDonald ${ }^{1}$, Jaeyun Moon ${ }^{3}$, Bo Feng ${ }^{3}$, \\ G.P. Peterson ${ }^{3}$, Han Gi Chae ${ }^{1}$, and Satish Kumar ${ }^{1, a}$ \\ ${ }^{1}$ School of Materials Science and Engineering, Georgia Institute of Technology, Atlanta, \\ Georgia 30332, USA \\ ${ }^{2}$ L.A. Giannuzzi \& Associates LLC, 12580 Walden Run Dr, Fort Myers, FL 33913, USA \\ ${ }^{3}$ George W. Woodruff School of Mechanical Engineering, Georgia Institute of Technology, \\ Atlanta, Georgia 30332, USA
}

\begin{abstract}
Polyacrylonitrile (PAN) and PAN/carbon nanotube (CNT) based carbon fibers at various CNT content have been processed and their structural development was investigated using high resolution transmission electron microscope (HR-TEM). For CNT containing carbon fibers, the CNTs act as templating agents for the graphitic carbon structure development in their vicinity at the carbonization temperature of $1450{ }^{\circ} \mathrm{C}$, which is far below the graphitization temperature of PAN based carbon fiber $\left(>2200{ }^{\circ} \mathrm{C}\right)$. The addition of $1 \mathrm{wt} \% \mathrm{CNT}$ in the gel spun precursor fiber results in carbon fibers with a $68 \%$ higher thermal conductivity when compared to the control gel spun PAN based carbon fiber, and a $103 \%$ and 146\% increase over commercially available IM7 and T300 carbon fibers, respectively. The electrical conductivity of the gel spun PAN/CNT based carbon fibers also showed improvement over the investigated commercially available carbon fibers. Increases in thermal and electrical conductivities are attributed to the formation of the highly ordered graphitic structure observed in the HR-TEM images. Direct observation of the graphitic structure, along with improved transport properties in the PAN/CNT based carbon fiber suggest new applications for these materials.
\end{abstract}

Keywords: Polyacrylonitrile, carbon nanotube, carbon fiber, electrical conductivity, thermal conductivity

\footnotetext{
${ }^{a}$ Corresponding author, Tel: +1-404-894-7550; fax: +1-404-894-8780. E-mail: satish.kumar@mse.gatech.edu (Satish Kumar)
} 


\section{Introduction}

It has been demonstrated that carbon nanotubes (CNTs) act as a nucleating agent for polymer crystallization. This behavior has been observed for many different polymer/CNT composites where the polymers were polyethylene[1], polypropylene[2], nylon[3], poly(ethylene terephthalate)[4], poly(vinyl alcohol)[5], and polyacrylonitrile (PAN)[6, 7]. Coupled with the capability of nucleating behavior, CNTs have also been shown to act as templating agents for polymer orientation. Previous investigations have reported that when processed under shear flow, polymer molecules in the vicinity of CNTs can form a highly ordered interphase region (e.g. oriented crystal structure)[1].

Among various polymers, PAN is of significant interest due to its predominance as a precursor for carbon fiber manufacturing $[8,9]$. Carbon fiber is a unique material to the extent that the material properties span a wide range of thermo-physical properties that can be tailored to the desired application, allowing for a vast range of material properties. By increasing the final heat treatment temperature of PAN based carbon fibers, increases in tensile modulus, electrical conductivity, and thermal conductivity have been observed[10, 11]. This is due to the increasing graphitic structure order in the fiber as the carbonization/graphitization temperature is increased, resulting in commercially available PAN based carbon fiber with tensile modulus ranging from 230 to $588 \mathrm{GPa}$, electrical conductivities of $55-143 \mathrm{kS} / \mathrm{m}$, and thermal conductivities of 5 to 152 $\mathrm{W} / \mathrm{m} / \mathrm{K}$ as reported by the manufacturer. However, improvements in tensile modulus, and electrical and thermal conductivity typically are achieved at the expense of tensile and compressive strength due to the large crystal grain formation of the graphitic structure. Fibers such as high modulus Toray M60J possess a tensile strength of $3.9 \mathrm{GPa}$, compressive strength of $1.0 \mathrm{GPa}[12]$, tensile modulus of $588 \mathrm{GPa}$, thermal conductivity of $0.363 \mathrm{cal} / \mathrm{cm} / \mathrm{s} /{ }^{\circ} \mathrm{C}(152$ 
$\mathrm{W} / \mathrm{m} / \mathrm{K}$ ), and electrical conductivity of $143 \mathrm{kS} / \mathrm{m}$. In comparison, intermediate modulus Toray $\mathrm{T} 800 \mathrm{H}$ possesses a tensile strength of $5.5 \mathrm{GPa}$, compressive strength of $2.3 \mathrm{GPa}[12]$, tensile modulus of $294 \mathrm{GPa}$, thermal conductivity of $35 \mathrm{~W} / \mathrm{m} / \mathrm{K}$, and electrical conductivity of $71 \mathrm{kS} / \mathrm{m}$ as reported by the manufacturer.

Experimental pitch/CNT[13] and PAN/CNT[14-17] based carbon fibers have previously been processed. PAN/CNT based carbon fibers have shown promising mechanical properties, with tensile strength of $3.2-5.5 \mathrm{GPa}$ (max single filament test: $7.3 \mathrm{GPa}$ ) and tensile modulus of 253 - $463 \mathrm{GPa}[14-17]$. It has been shown that both graphitic and turbostratic graphitic structures can be developed at relatively low carbonization temperatures $\left(800-1300{ }^{\circ} \mathrm{C}\right)[14-16,18,19]$, which is about $1000{ }^{\circ} \mathrm{C}$ lower than the temperature required for the graphitic structure formation of PAN based carbon fiber[8]. The highly ordered graphitic structure developed within the turbostratic graphitic matrix is expected to improve the transport properties (electrical and thermal conductivities) of the PAN/CNT based carbon fibers as compared to the traditional PAN based carbon fibers.

The thermal conductivity of PAN based carbon fibers is directly related to the concentration of point defects consisting of vacancies, interstitial atoms, and impurities, as well as the crystalline perfection and orientation. As the carbonization or graphitization heat treatment temperature is increased, the concentration of point defects is reduced and the crystalline perfection increases, thereby resulting in an improved thermal conductivity. Increasing the heat treatment temperature of a PAN based carbon fiber from $1500-2100{ }^{\circ} \mathrm{C}$ resulted in a thermal conductivity increase of 20.2 to $69.3 \mathrm{~W} / \mathrm{m} / \mathrm{K}[11]$, or over $350 \%$. Other methods of increasing PAN based carbon fiber thermal conductivity include the growth of CNTs on the surface of commercial carbon fibers, such as PAN based T1000GB (Toray) and pitch based K13D 
(Mitsubishi). The thermal conductivity of T1000GB increased 47\%, from 12.6 to $18.6 \mathrm{~W} / \mathrm{m} / \mathrm{K}$ following CNT grafting onto the carbon fiber surface[20].

It is well understood that the thermal conductivity in carbon fibers occurs through electron and phonon contributions. The electron contribution at room temperature is known to be $\sim 0.40-0.66 \mathrm{~W} / \mathrm{m} / \mathrm{K}[21,22]$, which is $\sim 10 \%$ of the reported thermal conductivity of commercial fibers such as IM7 $(5.4 \mathrm{~W} / \mathrm{m} / \mathrm{K})$. This suggests that the thermal conductivity of PAN based carbon fibers is largely due to phonon contributions. The thermal conductivity of CNTs is also a phonon dominated process which is dependent upon CNT length[23, 24], diameter[25, 26], purity[24], and degree of functionalization[27]. As described by the Debye equation[28], the lattice thermal conductivity is dependent upon the phonon relaxation time, specific heat, and phonon group velocity. Due to the estimated phonon mean free path $(100 \mathrm{~nm}-1 \mu \mathrm{m})$ in SWNTs, the thermal conductivity will be dependent upon the length of the SWNT, where SWNTs with lengths shorter than a few $\mu \mathrm{m}$ will exhibit ballistic behavior[29]. Measurements on individual MWNTs indicate that the thermal conductivity increases as the number of walls decreases, which has been attributed to the interactions of phonons and electrons between the MWNT walls, and that as the diameter (number of walls) increases so do the phonon and electron interactions which reduces the thermal conductivity[26]. Similarly, the thermal conductivity is also diameter dependent for SWNTs due to the lower probability for Umklapp scattering for smaller diameter tubes, as well as evidence that the phonon group velocity increases as the SWNT diameter decreases[30]. Maximum thermal conductivity in MWNTs $(\sim 3000 \mathrm{~W} / \mathrm{m} / \mathrm{K})$ was measured at $\sim 320 \mathrm{~K}[31], \sim 200 \mathrm{~K}$ higher temperature than that observed in highly ordered pyrolytic graphite (HOPG)[32]. It was also observed that the thermal conductivities of MWNT mats[33] and aligned SWNT rope films[34] are much lower than those of individual MWNTs[31] and 
SWNTs[28, 35], indicating that tube-tube contact thermal resistance[36] greatly reduces the thermal conductivity in CNT bundles. The thermal conductivities of polymer/CNT composites are also strongly dependent on the type of the CNT (e.g., SWNT or MWNT), the CNT length[37], CNT purity[38, 39], quality of CNT dispersion[40], and on the type and degree of functionalization of the CNT[37].

Electrical conductivity enhancement in polymer/CNT nanocomposites is well understood from percolation theory[41]. CNT alignment can be detrimental to electrical conductivity enhancement in polymer/CNT composites due to the inability of the CNTs to efficiently form a percolation network [42-46]. With electrical conductivities on the order of $\sim 10^{4}-10^{5} \mathrm{~S} / \mathrm{m}$, PAN based carbon fibers provide an electrically conducting matrix that surrounds the highly conducting CNTs such that increases in electrical conductivity are expected at low CNT volume fractions of CNTs despite the high degree of CNT orientation within the anisotropic carbon fiber.

In this investigation, the microstructure development of PAN and PAN/CNT based carbon fibers was investigated by HR-TEM and wide-angle x-ray diffraction (WAXD). The electrical, thermal, and mechanical properties of PAN and PAN/CNT based carbon fibers are correlated with the microstructure. Commercial PAN based carbon fibers, T300 and IM7 are also studied for comparison.

\section{Experimental}

2.1 Materials and fiber processing

Poly(acrylonitrile-co-methacrylic acid) (PAN-co-MAA, MAA content=4 wt $\%$ ) with viscosity average molecular weights of 453,000 g/mol, 513,000 g/mol, and 964,000 g/mol were obtained from Japan Exlan (Osaka, Japan). Three different types of CNTs (CNT-A, CNT-B, and 
CNT-C) were obtained from Continental Carbon Nanotechnologies, Inc. (Lot \# XOC231U), Unidym, Inc. (Lot \# XO122UA), and SouthWest Nanotechnology (SMW200), respectively. Average diameter $(2.7,3.0$, and $12.1 \mathrm{~nm})$ and number of walls (3.0, 3.0, and 10.5) were determined by TEM and CNT impurity content (1.1, 3.3, and 2.3 wt $\%$ ) by TGA for CNT-A, CNT-B, and CNT-C, respectively. For polymer solution and CNT dispersion, $N, N-$ dimethylformamide (DMF) was used after distillation.

For control PAN solution, the polymer was dissolved in DMF at $90{ }^{\circ} \mathrm{C}$ for $2 \mathrm{~h}$. Four different PAN/CNT composite solutions (PAN/CNT-A (0.42 wt $\%)$, PAN/CNT-A (1 wt $\%$ ), PAN/CNT-B (0.5 wt $\%)$, and PAN/CNT-C (0.5 wt $\%))$ were prepared as described elsewhere[47]. The solid concentration for all solutions was $10.5 \mathrm{~g} / \mathrm{dL}$. For PAN/CNT-A and PAN/CNT-C solutions, copolymer with a viscosity average molecular weight of 513,000 g/mol was used, while PAN/CNT-B solution was prepared using a mixture of two copolymers $(453,000$ and 964,000 g/mol). The weight fraction of high molecular weight PAN-co-MAA $(964,000 \mathrm{~g} / \mathrm{mol})$ was $15 \mathrm{wt} \%$ and that of the low molecular weight PAN-co-MAA $(453,000 \mathrm{~g} / \mathrm{mol})$ was $85 \mathrm{wt} \%$.

PAN and PAN/CNT precursor fibers were gel spun as a 100 filament tow using laboratory scale multi-filament fiber spinning machine (Hills Inc., Melbourne, FL). The flow rate for fiber spinning was maintained at $0.5 \mathrm{cc} / \mathrm{min} / \mathrm{hole}$ and the gelation medium was $-50{ }^{\circ} \mathrm{C}$ methanol for all GT PAN and GT PAN/CNT fibers, with the exception of the GT PAN/CNT-B fibers, which utilized a room temperature methanol coagulation. The as-spun draw ratio was 3 and the post-spin draw ratio was as high as 13 . The post-spin drawing was conducted using a multi-step drawing process and the drawing temperature was as high as $185^{\circ} \mathrm{C}$. The 100 filament tow precursor fibers were subsequently stabilized and carbonized using continuous carbonization equipment (Harper International Co, Buffalo, NY). The stabilization and carbonization 
temperatures were as high as $310{ }^{\circ} \mathrm{C}$ and $1450{ }^{\circ} \mathrm{C}$, respectively. Tensions as high as $51 \mathrm{MPa}$ during stabilization and $44 \mathrm{MPa}$ during carbonization were achieved based upon the precursor fiber diameter. Sample designation of the final processed gel spun PAN based carbon fiber is GT PAN. It should be noted that the GT PAN carbon fiber presented in this manuscript is distinct from other recent publications[48] where as a result of further processing improvements even higher mechanical properties have been reported and the processing, structure, property relationships of the gel spun PAN based carbon fibers are discussed in further detail. For the composite carbon fibers, GT PAN/CNT-A $(0.42 \mathrm{wt} \%)$ and GT PAN/CNT-A (1.0 wt $\%)$ were processed from two distinct precursor fibers. The GT PAN/CNT-B1 (0.5 wt $\%)$ and GT PAN/CNT-B2 (0.5 wt\%) carbon fibers were processed from the same precursor fiber. Differences in temperature profiles and applied strain during stabilization and carbonization contributed to the manufacture of two distinct carbon fibers, GT PAN/CNT-B1 (0.5 wt $\%)$ and GT PAN/CNT-B2 (0.5 wt $\%)$, from the same precursor fiber. GT PAN/CNT-C (0.5 wt $\%)$ was processed from multi-wall carbon nanotube (SMW200 MWNT) containing precursor fiber.

\subsection{Characterization}

Single filament tensile testing was performed using a FAVIMAT+ tensile testing instrument with a $25.4 \mathrm{~mm}$ gauge length, at a strain rate of $0.1 \% / \mathrm{s}$. Fiber linear density was measured on each tensile specimen using the inline vibroscope on the FAVIMAT+. The Supplementary Information provides analysis of a single filament effective diameter along a length of $25 \mathrm{~mm}$, supporting the use of the inline vibroscope for linear density measurements. WAXD was conducted on 200 filament bundles using previously described methods[6]. Scanning electron microscopy (SEM) was performed on a Zeiss Ultra 60 FE-SEM at an accelerating voltage of $2 \mathrm{keV}$. HR-TEM was performed on a FEI Tecnai F30 at an accelerating 
voltage of $80 \mathrm{keV}$. Samples were prepared for observation by HR-TEM on a FEI NOVA Nanolab 200 focused ion beam (FIB)/SEM. Individual fiber samples were mounted perpendicularly to the surface of Copper 3-Post Omniprobe grids (Electron Microscopy Sciences) using Epo-Tek 353ND epoxy (Gatan, Inc.). Samples were then FIB thinned using gallium ions at $30 \mathrm{keV}$ followed by a low energy polish at $5 \mathrm{keV}$. Thermal and electrical conductivity measurements were performed on individual carbon fibers using a DC Thermal Bridge Method (DCTBM) described previously[49] and standard four-probe approach, respectively. Three filaments were tested using the DCTBM approach to ensure accuracy and the values were averaged to obtain the thermal and electrical conductivity values.

\section{Results and Discussion}

3.1 Structure development of the PAN and PAN/CNT based carbon fibers

HR-TEM micrographs of the transverse cross-section of PAN based carbon fibers are shown in Fig. 1. For comparison, those of commercial carbon fibers (T300 and IM7) are shown in Fig. 1a and 1b, respectively. T300 (Fig. 1a1 and 1a2) shows a random crystallite orientation with smaller crystallites in the lateral direction as compared to the larger and oriented crystallites of IM7 (Fig. 1b1 and 1b2). WAXD analysis results showed that T300 has a lateral crystal size $\left(L_{002}\right)$ of $1.4 \mathrm{~nm}$, which is marginally smaller than those of $1.6 \mathrm{~nm}$ for IM7 and the GT PAN based carbon fibers (Table 1). T300 exhibits a core of $\sim 2.7 \mu \mathrm{m}$ in diameter, and a surrounding radial sheath $\sim 2.2 \mu \mathrm{m}$ wide, which can be observed from the FIB thinned section by SEM in the Supplementary Information (Fig. S1a), and has been observed using other techniques[50, 51]. Differences in internal structure between the T300 sheath (Fig. 1a1) and core (Fig. 1a2) were observed by HR-TEM. Similar FIB thinning of the gel spun GT PAN based carbon fiber in Fig. 
S1b does not show the same sheath-core structure, but a uniform structure throughout the fiber cross-section.
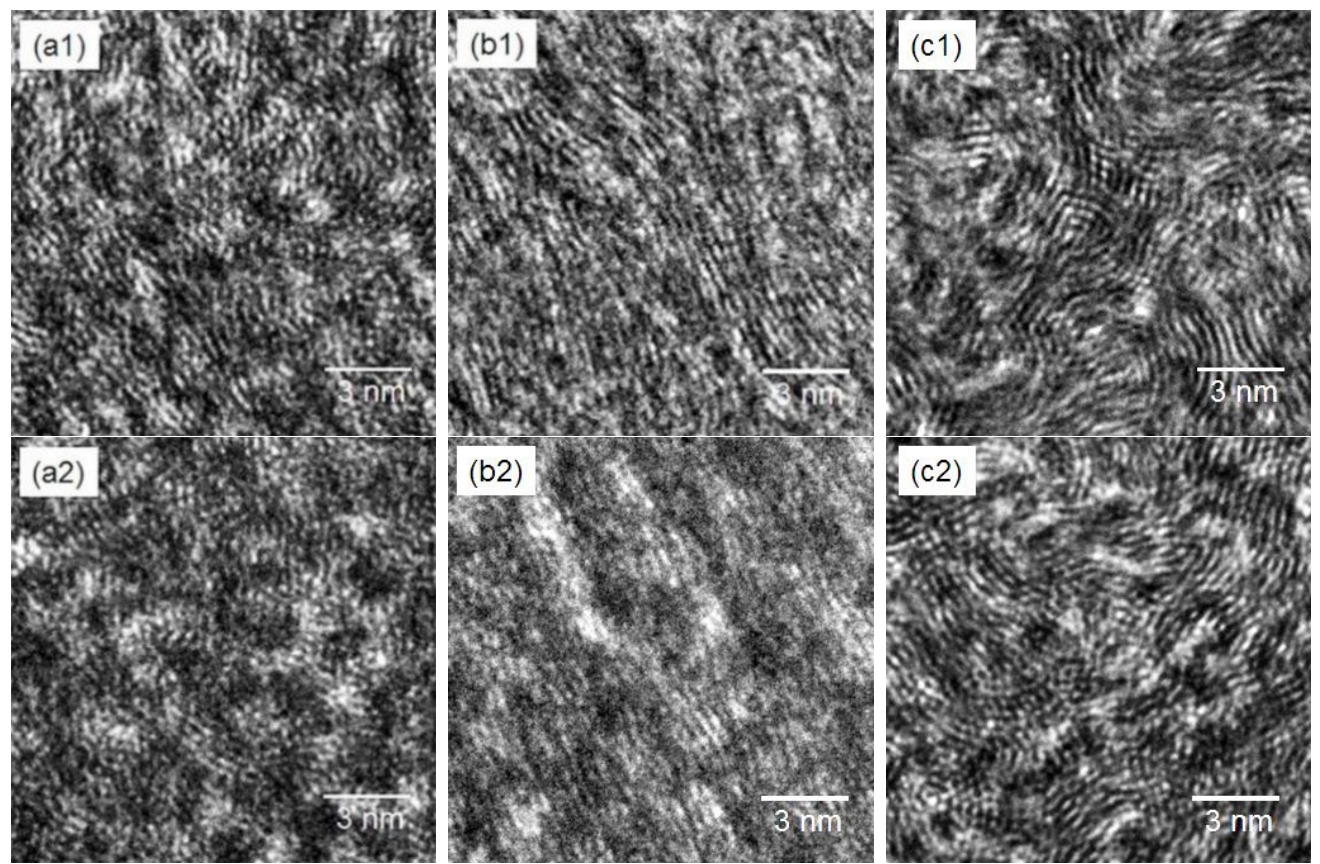

Fig. 1 - HR-TEM transverse cross-section (fiber axis into and out of page) images of (a1 and a2) T300, (b1 and b2) IM7, and (c1 and c2) GT PAN carbon fiber. The images of (a1), (b1), and (c1) are from fiber edge and those of (a2), (b2), and (c2) are from fiber center.

Structural parameters determined by WAXD for the gel spun GT PAN and PAN/CNT based carbon fibers and of the commercial T300 and IM7 carbon fibers are presented in Table 1. As noted earlier, the $L_{002}$ and $L_{10}$ crystal sizes of the GT PAN based carbon fiber are slightly larger than that of the T300 carbon fiber. In addition, the gel spun PAN/CNT based carbon fibers also showed similar structural parameters as compared to those of the GT PAN based carbon fiber. However, orientation characterization of the GT PAN and PAN/CNT based carbon fiber exhibits differences in the azimuthal scans of the $2 \theta \sim 25^{\circ}$ peak, which can be fitted to a single curve in the case of the PAN based carbon fiber, and can be de-convoluted into two peaks in the GT PAN/CNT-A and GT PAN/CNT-B based carbon fiber as described elsewhere[15, 16]. De- 
convoluting the two peaks of the azimuthal scan allows for the area fraction of the two peaks to be determined, which can be used as an estimate of the volume fraction of the two regions corresponding to the turbostratic matrix and the highly ordered graphitic region as shown in Fig. 2. In addition, the orientation factors of both the turbostratic matrix $\left(f_{002, \text { matrix }}\right)$ and the highly ordered $(\mathrm{HO})$ graphitic region $\left(f_{002, \mathrm{HO}}\right)$ can be determined, and are presented in Table 1 . It is interesting to note the high level of orientation associated with the highly ordered graphitic region in the GT PAN/CNT-A and GT PAN/CNT-B based carbon fibers, with $f_{002, H O} \geq 0.97$. It is also interesting that PAN/CNT-C $(0.5 \mathrm{wt} \%)$ exhibits an azimuthal scan similar to that of the control GT PAN carbon fiber. Considering that CNT-C is best described as a MWNT (average number of walls $=10.5$ ), and CNT-A and CNT-B are considered FWNTs (average number of walls $=2.6$, it can be surmised that the presence of the $\mathrm{HO}$ region in the azimuthal scan is associated only with the templated graphitic region and not from the repeat crystallographic planes of the CNT walls. Therefore, due to the absence of the second peak in the azimuthal scan of GT PAN/CNT-C $(0.5 \mathrm{wt} \%)$ and its presence in the GT PAN/CNT-A $(0.5 \mathrm{wt} \%)$ and GT PAN/CNT-B carbon fibers, it can be concluded that the carbon fibers produced with CNT-A and CNT-B exhibit graphitic templating behavior.

Table 1. Structural parameters of the GT PAN and PAN/CNT based carbon fibers. Structural parameters of the commercial PAN based carbon fibers are also listed for comparison.

\begin{tabular}{|c|c|c|c|c|c|c|c|c|}
\hline & T300 & IM7 & $\begin{array}{c}\text { GT } \\
\text { PAN }\end{array}$ & $\begin{array}{c}\text { GT } \\
\text { PAN/CNT-A } \\
(0.42 \mathrm{wt} \%)\end{array}$ & $\begin{array}{c}\text { GT } \\
\text { PAN/CNT-A } \\
(1 \mathrm{wt} \%)\end{array}$ & $\begin{array}{c}\text { GT PAN/CNT- } \\
\text { B1 (0.5 wt\%) }\end{array}$ & $\begin{array}{c}\text { GT PAN/CNT- } \\
\text { B2 (0.5wt\%) }\end{array}$ & $\begin{array}{c}\text { GT PAN/CNT-C } \\
(0.5 \mathrm{wt} \%)\end{array}$ \\
\hline $\boldsymbol{f}_{\mathbf{0 0 2 , \text { matrix }}}$ & 0.77 & 0.83 & 0.86 & 0.87 & 0.86 & 0.83 & 0.87 & 0.86 \\
\hline $\boldsymbol{f}_{\mathbf{0 0 2}, \mathbf{H O}}$ & - & - & - & $0.98(1.4)^{*}$ & $0.97(2.0)^{*}$ & $0.99(0.7)^{*}$ & $0.99(0.9)$ & - \\
\hline $\mathbf{F W H M}$ & 35.0 & 30.2 & 28.1 & 26.5 & 29.6 & 31.5 & 26.5 & 26.3 \\
\hline $\boldsymbol{d}_{(\mathbf{0 0 2})}(\mathbf{n m})$ & 0.349 & 0.348 & 0.347 & 0.346 & 0.347 & 0.349 & 0.346 & 0.347 \\
\hline $\boldsymbol{L}_{(\mathbf{0 0 2})}(\mathbf{n m})$ & 1.4 & 1.6 & 1.6 & 1.7 & 1.6 & 1.5 & 1.8 & 1.7 \\
\hline $\boldsymbol{L}_{(\mathbf{1 0 )})}(\mathbf{n m})$ & 2.0 & 2.1 & 2.5 & 2.5 & 2.2 & 2.0 & 2.1 & 2.3 \\
\hline
\end{tabular}

* Values in parenthesis indicate the volume fraction of the HO graphitic region as determined through peak deconvolution of the $2 \theta \sim 25^{\circ}$ azimuthal scan.

${ }^{\#}$ FWHM of the $2 \theta \sim 25^{\circ}$ azimuthal peak. 


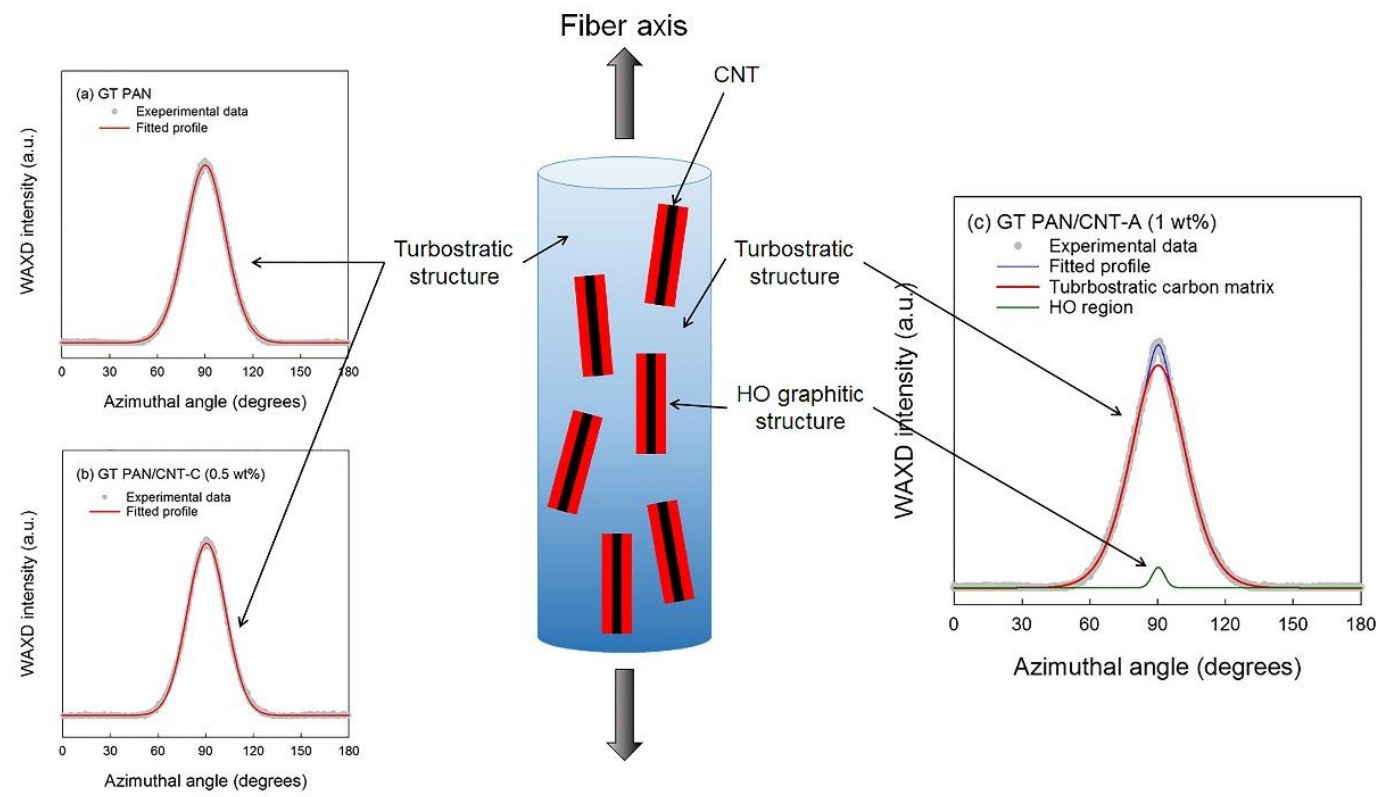

Fig. 2 - Azimuthal scans of the gel spun (a) GT PAN, (b) GT PAN/CNT-C (0.5 wt $\%$ ) and (c) GT PAN/CNT-A (1.0 wt\%) fibers. The azimuthal scans of (a) and (b) can be fitted using a single fitting curve while (c) is fitted with two curves. The additional fitting curve in (c) is attributed to the highly ordered region formed by the CNT and the CNT graphitic template region. Schematic description of the carbon fibers is also shown to illustrate the turbostratic carbon matrix, templated graphitic structure, and CNTs.

In contrast to the turbostratic crystallites observed in the PAN based carbon fibers, a highly ordered graphitic region is observed surrounding the CNTs and CNT bundles in the PAN/CNT based carbon fibers as shown in Fig. 3. Given that the CNTs used in this study have an average diameter of 2.7 and $3.0 \mathrm{~nm}$ for CNT-A and CNT-B, respectively, and both have an average number of walls of 2.6[47], the CNT templated graphitic structure can be directly observed. In the case of GT PAN/CNT-B1 (0.5 wt $\%)$ as many as 12-14 graphitic layers are developed beyond the CNT bundle structure as shown in Fig. $3 \mathrm{~b} 1$ and 3b2, which can be used to depict the formation and growth of the CNT templated graphitic structure. In the right half of Fig. 3b2, three distinct CNTs can be observed on the side of the CNT bundle. Considering that the number of walls for the individual CNTs is 2.6, it can be estimated that the concentrically template graphitic structure contains $\sim 9-11$ graphitic layers. As the templated graphitic structure 
from the surface of each CNT begins to grow and form increasing concentric layers, its associated templated graphitic structures begin to impinge upon the neighboring CNT's templated graphitic structure. As this occurs, the templated graphitic structure on each individual CNT begins to form a continuous graphitic structure that begins to envelope the CNTs. It can also be noted that, as the CNT bundle increases in size (greater number of CNTs within the bundle), the available surface area for templated growth begins to diminish, and if CNTs are aggregated, graphitic templating is not possible due to the lack of PAN molecules separating the CNTs prior to stabilization and carbonization. This signifies the importance of the individualized and exfoliated CNTs within the precursor fiber so that maximum surface area interaction can occur between the CNT surface and the PAN matrix prior to carbonization and formation of the graphitic CNT templated structure.
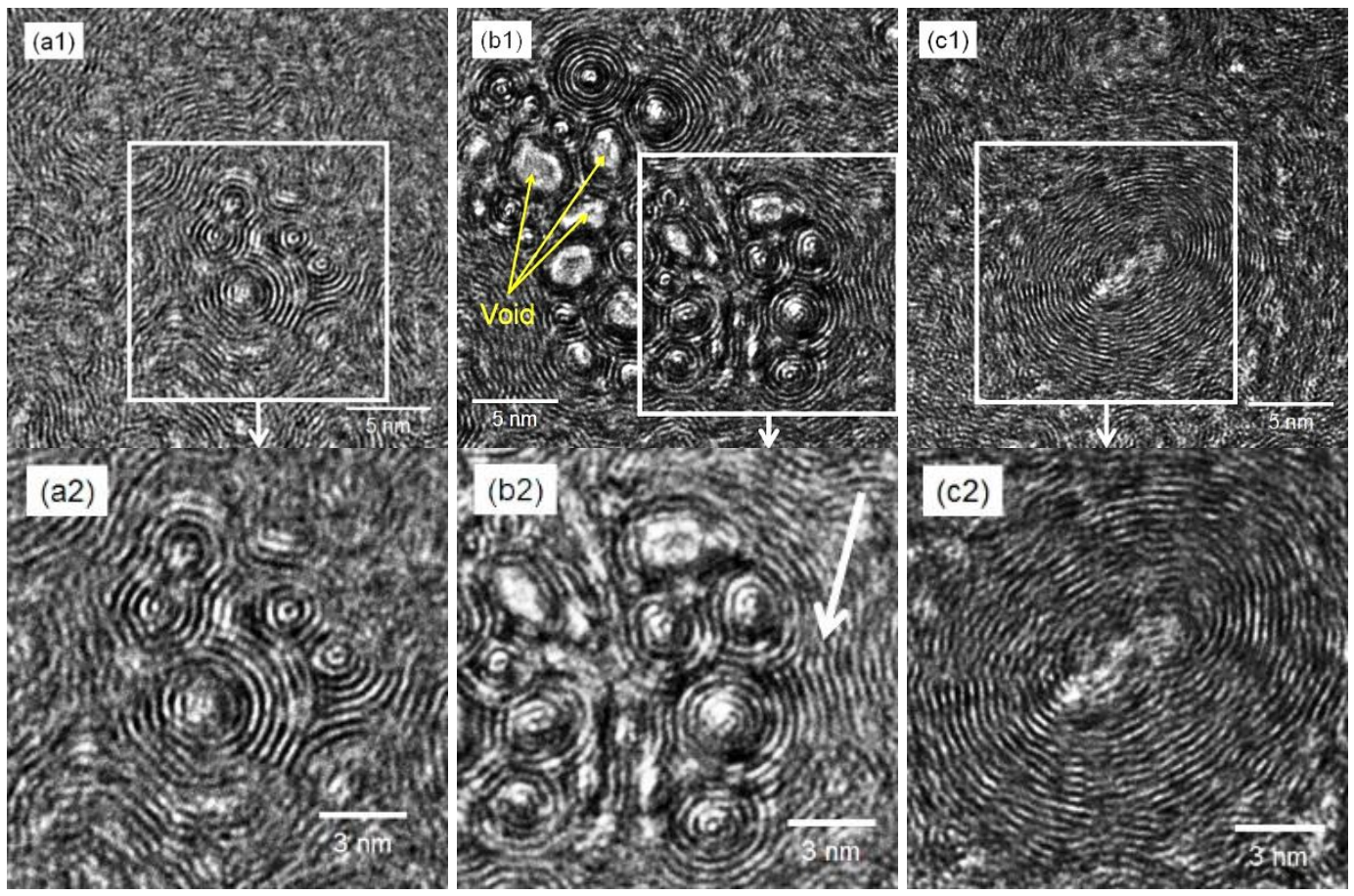

Fig. 3 -. HR-TEM transverse cross-sectional images of (a1 and a2) the GT PAN/CNT-A $(0.42$ wt\%), (b1 and b2) the GT PAN/CNT-B1 (0.5 wt \%), and (c1 and c2) the GT PAN/CNT-C (0.5 $\mathrm{wt} \%)$. The arrow in (b2) shows the evidence of graphitic templating and epitaxial growth at the outside most surface of the CNT bundle. 
3.2 Thermal conductivity of the PAN and PAN/CNT based carbon fibers

The PAN and PAN/CNT based carbon fibers exhibited higher room temperature thermal conductivities than the commercially available T300 and IM7 carbon fibers during single filament testing using the DCTBM as shown in Table 2. T300 and IM7 carbon fibers have manufacturer reported room temperature thermal conductivities of $0.025 \mathrm{cal} / \mathrm{s}-\mathrm{cm}-{ }^{\circ} \mathrm{C}(10.5$ $\mathrm{W} / \mathrm{m} / \mathrm{K})$ and $3.12 \mathrm{Btu} / \mathrm{hr}^{-\mathrm{ft}-{ }^{\circ} \mathrm{F}}(5.4 \mathrm{~W} / \mathrm{m} / \mathrm{K})$, respectively. Using the DCTBM, room temperature thermal conductivities of $13.6 \mathrm{~W} / \mathrm{m} / \mathrm{K}$ and $16.5 \mathrm{~W} / \mathrm{m} / \mathrm{K}$ were measured for T300 and IM7 carbon fibers (Table 2). The DCTBM used has an experimental uncertainty of $\pm 11 \%$ [49], while the thermal conductivity measurement methods of T300 and IM7 are not explicitly outlined by the manufacturers. Single filament thermal conductivity experiments of high strength PAN based carbon fiber (Toray T1000GB) using an AC modified calorimetry method measured a thermal conductivity of $12.6 \mathrm{~W} / \mathrm{m} / \mathrm{K}[20]$. Compared to the supplier reported value of $(32.1 \mathrm{~W} / \mathrm{m} / \mathrm{K})$ by Toray, differences in thermal conductivity values exist and are dependent upon the testing procedure.

The GT PAN carbon fiber exhibits a room temperature thermal conductivity of 20.0 $\mathrm{W} / \mathrm{m} / \mathrm{K}$ using the DCTBM, a $47 \%$ and $21 \%$ increase as compared to T300 and IM7, respectively. The GT PAN/CNT-A (1.0 wt\%) carbon fiber exhibits the highest room temperature thermal conductivity measured at $33.5 \mathrm{~W} / \mathrm{m} / \mathrm{K}$. Considering the similar processing conditions of the PAN and PAN/CNT based carbon fibers, increases in PAN/CNT based carbon fiber over PAN based carbon fiber thermal conductivity can be attributed to the inclusion of the CNTs and their influence on the carbon structure, resulting in the graphitic templated region as observed by the TEM study. Fig. 4a shows the thermal conductivity of various PAN and PAN/CNT based carbon fibers as a function of temperature. Thermal conductivity increases as a function of temperature 
for all the fibers, which is expected for the turbostratic structure formed in PAN based carbon fiber[52]. To understand the effect of the CNTs and the templated graphitic structure within the PAN/CNT based carbon fibers, the thermal conductivity enhancement at $\sim 295 \mathrm{~K}$ is shown in Fig. 4b. The thermal conductivity enhancement is described by the relationship $k / k_{m}$ where $k$ is the thermal conductivity of the gel spun PAN/CNT based carbon fiber and $k_{m}$ is the thermal conductivity of the gel spun PAN based carbon fiber. In all cases, the thermal conductivity is increased with the addition of CNTs.

Table 2. Thermal and electrical conductivity of the PAN and PAN/CNT based carbon fibers at $\sim 295 \mathrm{~K}$ as determined by the DCTBM. Tensile properties as determined by individual filament testing at $25.4 \mathrm{~mm}$ gauge length.

\begin{tabular}{|c|c|c|c|c|c|c|c|c|}
\hline & T300 & IM7 & GT PAN & $\begin{array}{c}\text { GT } \\
\text { PAN/CNT-A } \\
(0.42 \mathrm{wt} \%)\end{array}$ & $\begin{array}{c}\text { GT } \\
\text { PAN/CNT- } \\
\text { A (1 wt\%) }\end{array}$ & $\begin{array}{c}\text { GT } \\
\text { PAN/CNT-B1 } \\
(0.5 \mathrm{wt} \%)\end{array}$ & $\begin{array}{c}\text { GT } \\
\text { PAN/CNT-B2 } \\
(0.5 \mathrm{wt} \%)\end{array}$ & $\begin{array}{c}\text { GT } \\
\text { PAN/CNT-C } \\
(0.5 \mathrm{wt} \%)\end{array}$ \\
\hline $\begin{array}{c}\text { Thermal } \\
\text { conductivity } \\
(\mathrm{W} / \mathrm{m} / \mathrm{K}) \text { at } 295 \\
\mathrm{~K}\end{array}$ & $\begin{array}{c}13.6 \\
(10.5)^{\ddagger}\end{array}$ & $\begin{array}{c}16.5 \\
(5.4)^{\ddagger}\end{array}$ & 20.0 & 23.7 & 33.5 & 31.0 & Not measured & $\begin{array}{c}\text { Not } \\
\text { measured }\end{array}$ \\
\hline $\begin{array}{c}\text { Electrical } \\
\text { conductivity } \\
(\mathrm{kS} / \mathrm{m}) \text { at 295 K }\end{array}$ & $\begin{array}{c}54.0 \\
(58.8)^{\ddagger}\end{array}$ & $\begin{array}{c}59.6 \\
(66.7)^{\ddagger}\end{array}$ & 61.3 & 74.2 & 70.0 & 63.6 & Not measured & $\begin{array}{c}\text { Not } \\
\text { measured }\end{array}$ \\
\hline \begin{tabular}{c} 
Diameter $(\mu \mathrm{m})$ \\
\hline $\begin{array}{c}\text { Tensile strength } \\
(\mathrm{GPa})^{*}\end{array}$
\end{tabular} & $\begin{array}{c}6.8 \pm 0.2 \\
(7)^{\ddagger}\end{array}$ & $\begin{array}{c}5.2 \pm 0.2 \\
(5.2)^{\ddagger}\end{array}$ & $4.9 \pm 0.3$ & $5.7 \pm 0.3$ & $6.2 \pm 0.5$ & $5.2 \pm 0.4$ & $4.9 \pm 0.2$ & $6.1 \pm 0.4$ \\
\hline $\begin{array}{c}\text { Compliance } \\
\text { corrected } \\
\text { tensile modulus } \\
(\mathrm{GPa})^{* *}\end{array}$ & $\begin{array}{c}5.5 \pm 0.8 \\
(5.5-5.7)^{\ddagger}\end{array}$ & $4.2 \pm 1.0$ & $3.2 \pm 0.8$ & $2.0 \pm 0.4$ & $3.1 \pm 0.8$ & $3.1 \pm 0.8$ & $4.0 \pm 0.9$ \\
\hline
\end{tabular}

* Tensile properties are measured at 1 inch gauge length.

** Compliance corrected tensile moduli are obtained by testing fibers at various gauge length as described elsewhere[53].

$\neq$ The values in parenthesis are manufacturer reported data. 

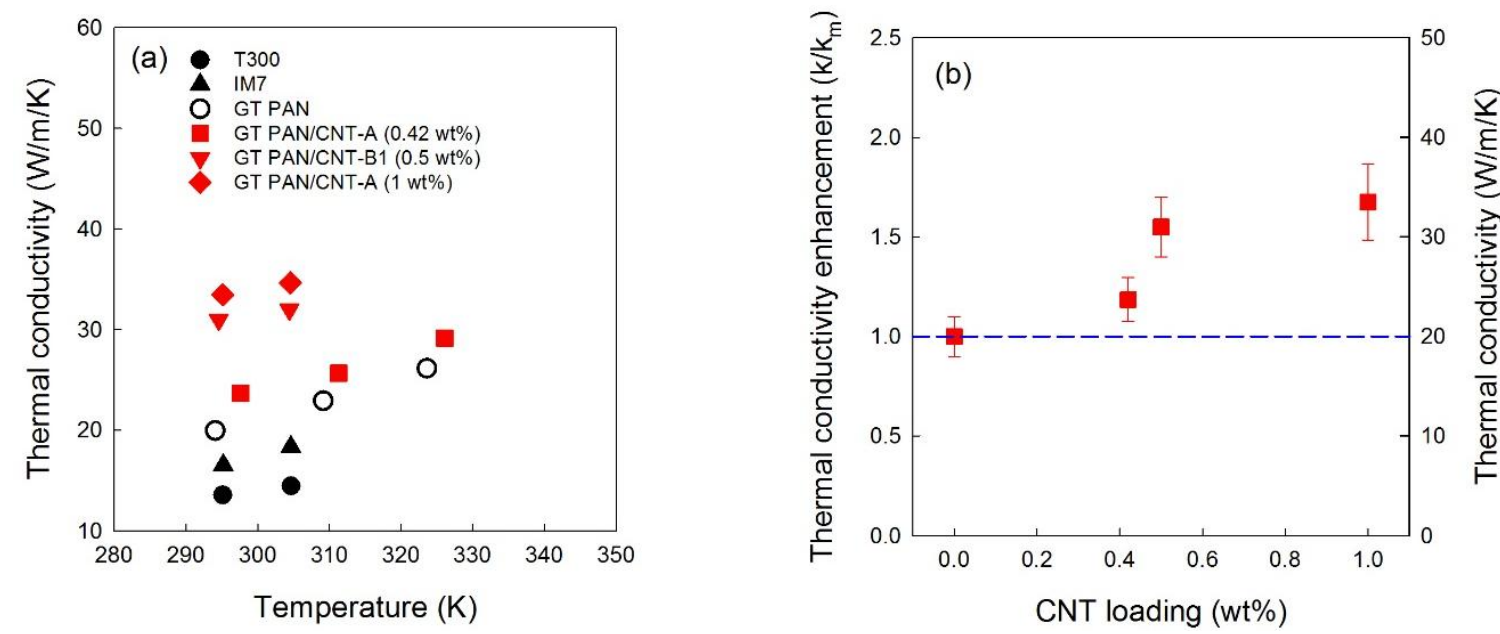

Fig. 4 - (a) Thermal conductivities of various carbon fibers as a function of temperature and (b) thermal conductivity enhancement in the PAN/CNT based carbon fibers (T $\sim 295 \mathrm{~K})$. The $k_{m}$ is the thermal conductivity of the GT PAN based carbon fiber. All thermal conductivity values were measured using DCTBM.

The thermal conductivity of the PAN/CNT based carbon fibers can be affected by both the presence of CNT and the formation of the highly ordered graphitic structure in the vicinity of CNTs. Due to the high thermal conductivity of CNTs $(3000-3500 \mathrm{~W} / \mathrm{m} / \mathrm{K})$ and HOPG (2000 $\mathrm{W} / \mathrm{m} / \mathrm{K}$ ) at room temperature as compared to the thermal conductivity of the PAN based carbon fibers $(\mathrm{T} 300-13.6 \mathrm{~W} / \mathrm{m} / \mathrm{K}, \mathrm{IM} 7-16.5 \mathrm{~W} / \mathrm{m} / \mathrm{K})$, even a relatively low amount of CNTs which exhibit strong graphitic interphase formation will enhance the thermal conductivity as compared to PAN based carbon fibers without CNTs or a graphitic interphase. Using the curve fitting data of the WAXD azimuthal scans shown in Fig. 2, the thermal conductivity of the highly ordered graphitic region perpendicular $\left(K_{\perp}\right)$ and parallel $\left(K_{\|}\right)$to the fiber direction can be determined using equations 1 and 2, respectively[32].

$$
\begin{array}{ll}
K_{\perp}=K_{a}\left[1-\left(1-\frac{K_{c}}{K_{a}}\right)\left\langle\cos ^{2} \phi\right\rangle\right] & \text { eq. } 1 \\
K_{\|}=K_{a}\left[1-\left(1-\frac{K_{c}}{K_{a}}\right)\left\langle\sin ^{2} \phi \cos ^{2} \phi\right\rangle\right] & \text { eq. } 2
\end{array}
$$


Where $K_{a}$ is the thermal conductivity along the fiber axis (perpendicular to the graphitic (002) plane), $K_{c}$ is the thermal conductivity perpendicular to the fiber axis (parallel to the graphitic (002) plane), and $\phi$ is the angle between the c-axis ((002) direction) and the fiber axis.

Since the highly ordered graphitic region in the vicinity of CNTs is assumed to possess similar structure to pyrolytic graphite[54], here we assumed $K_{a}$ of $1950 \mathrm{~W} / \mathrm{m} / \mathrm{K}$ and $K_{c}$ of 5.7 $\mathrm{W} / \mathrm{m} / \mathrm{k}$. The calculated thermal conductivities $\left(K_{\|}\right)$of the templated graphitic regions are listed in Table 3. In a similar fashion, the thermal conductivity of the graphitic region can also be predicted from the full width at half maximum (FWHM) intensity of the highly ordered graphitic region from the WAXD azimuthal scan. Using the relationship put forward by Bacon[55], where $I(\phi) \sim \cos ^{m} \phi$, where the higher the value of $m$ the greater the orientation of the graphitic structure, and the relationship of Fischbach[56], $\beta \sim 1.18 m^{-1 / 2}$, where $\beta$ (in radians) is the FWHM of the azimuthal scan, equations 3 and 4 can be used to determine the thermal conductivity of the bulk graphite based upon the crystal orientation. The calculated thermal conductivities $\left(K_{\|}\right)$of the templated graphitic regions are also listed in Table 3.

Table 3. FWHM of the highly ordered $(\mathrm{HO})$ region determined by WAXD azimuthal scans and the corresponding volume fraction of the $\mathrm{HO}$ region in parenthesis. Bacon's constant $\mathrm{m}$ is also used to quantify the orientation of the $\mathrm{HO}$ region. The thermal conductivities of the $\mathrm{HO}$ region were calculated using eq. 2 and eq. 4.

\begin{tabular}{|l|c|c|c|c|}
\hline & $\begin{array}{c}\text { FWHM }_{\text {azimuthal }} \\
\text { of HO region }\end{array}$ & $\begin{array}{c}\text { Bacon's } \\
\text { constant } m \text { of } \\
\text { HO region }\end{array}$ & $\begin{array}{c}K_{\|}(\mathrm{W} / \mathrm{m} / \mathrm{K}) \\
\text { by eq. } 2\end{array}$ & $\begin{array}{c}K_{\|}(\mathrm{W} / \mathrm{m} / \mathrm{K}) \\
\text { by eq. } 4\end{array}$ \\
\hline GT PAN/CNT-A $(0.42 \mathrm{wt} \%)$ & $6.3(1.4 \%)$ & 82 & 1939 & 1927 \\
\hline GT PAN/CNT-B1 $(0.5 \mathrm{wt} \%)$ & $5.6(0.7 \%)$ & 145 & 1946 & 1937 \\
\hline GT PAN/CNT-A $(1 \mathrm{wt} \%)$ & $7.9(2.0 \%)$ & 73 & 1945 & 1924 \\
\hline
\end{tabular}




$$
\begin{array}{ll}
K_{\perp}=K_{a}\left[1-\left(1-\frac{K_{c}}{K_{a}}\right)\left(\frac{m+1}{m+3}\right)\right] & \text { eq. } 3 \\
K_{\|}=K_{a}\left[1-\left(1-\frac{K_{c}}{K_{a}}\right)\left(\frac{1}{m+3}\right)\right] & \text { eq. } 4
\end{array}
$$

The thermal conductivities of PAN/CNT based carbon fibers can be approximated based on the measured thermal conductivity of the PAN based carbon fiber and the volume fraction of the $\mathrm{HO}$ regions determined from WAXD analysis. Using the parallel and series models to predict the thermal conductivities of the PAN/CNT based carbon fibers (eqs. 5 and 6, respectively), the upper and lower bounds of the theoretical thermal conductivities of the PAN/CNT carbon fibers $\left(k_{c}\right)$ are calculated and listed in Table 4.

$$
\begin{aligned}
& k_{c}=k_{p} V_{p}+k_{m} V_{m} \\
& k_{c}=\frac{1}{\left(\left(V_{m} / k_{m}\right)+\left(V_{p} / k_{p}\right)\right)}
\end{aligned}
$$

where, $k_{p}$ is the thermal conductivity of the highly graphitic region, $V_{p}$ is the volume fraction of the highly graphitic region, $k_{m}$ is the thermal conductivity of the turbostratic carbon fiber, and $V_{m}$ is the volume fraction of the turbostratic carbon fiber.

It has been reported that the thermal conductivity $(k)$ in polymer/CNT composites typically falls between the series and the parallel thermal conductivity approximations, but typically nearer the series model[57]. In the current study, it was also observed that the calculated thermal conductivities are between these models, suggesting that the measured values are valid. Discrepancies between the experimental data and the two predicting models can be attributed to the models not accounting for thermal resistance at the boundary between the turbostratic matrix and the CNT, turbostratic matrix and the graphitic interphase, CNT and the 
graphitic interphase, and CNT-CNT overlap and contact resistance. Defects inherent to the fibers are not taken into account in either the series or the parallel model. These defects can create phonon scattering, which is not accounted for using either of the two models. The HR-TEM image in Fig. $3 \mathrm{~b} 1$ is an example of the voids that can exist within the CNT bundles of the PAN/CNT based carbon fiber. These voids are not seen in the GT PAN carbon fiber since the CNT and CNT bundles are not present to form these voids, which will be discussed later.

Table 4. Predicted thermal conductivity of the PAN/CNT based carbon fibers using the parallel and series models.

\begin{tabular}{|l|c|c|c|}
\hline & $\begin{array}{c}k_{\mathrm{c}}(\text { Series Model }) \\
(\mathrm{W} / \mathrm{m} / \mathrm{K})\end{array}$ & $\begin{array}{c}k_{\mathrm{c}}(\mathrm{measured}) \\
(\mathrm{W} / \mathrm{m} / \mathrm{K})\end{array}$ & $\begin{array}{c}k_{\mathrm{c}}(\text { Parallel Model }) \\
(\mathrm{W} / \mathrm{m} / \mathrm{K})\end{array}$ \\
\hline GT PAN/CNT-A $(0.42 \mathrm{wt} \%)$ & 20.3 & 23.7 & 46.7 \\
\hline GT PAN/CNT-B1 $(0.5 \mathrm{wt} \%)$ & 20.1 & 31.0 & 33.4 \\
\hline GT PAN/CNT-A $(1.0 \mathrm{wt} \%)$ & 20.4 & 33.5 & 58.0 \\
\hline
\end{tabular}

\subsection{Electrical conductivity of the PAN and PAN/CNT based carbon fibers}

Generally, the electrical conductivity of PAN based carbon fiber scales with its tensile modulus[9]. As crystallite orientation increases so does tensile modulus. The improved orientation results in greater electron mobility along the fiber axis, resulting in an improved electrical conductivity. Fig. 5a plots the electrical conductivities of various carbon fibers as a function of their tensile modulus. It appears that the PAN based carbon fibers follow a linear trend and the PAN/CNT based carbon fibers follow their own linear trend, with enhanced electrical conductivities despite similar tensile moduli. Considering that the electrical conductivity in PAN based carbon fibers can be diminished by the presence of defects such as 
grain boundaries, dislocations, and point defects, which increase local electrical resistivity, the perfection within the fiber plays a critical role in the electron transport.

Fig. $5 \mathrm{~b}$ shows the electrical conductivity of various fibers as a function of temperature and Table 2 also provides the electrical conductivity at $295 \mathrm{~K}$. It is clear that the addition of CNTs leads to improvements in the electrical conductivity in the PAN/CNT based carbon fiber as compared to the PAN based carbon fiber. The GT PAN/CNT-A $(0.42 \mathrm{wt} \%)$ carbon fiber exhibits a $21 \%$ increase in electrical conductivity as compared to the GT PAN based carbon fiber, and a 24\% increase as compared to the IM7 carbon fiber. Both the GT PAN based carbon fiber and the GT PAN/CNT-A $(0.42 \mathrm{wt} \%)$ carbon fiber have similar orientation of turbostratic matrix $\left(f_{\text {matrix }}\right)$ and crystal size, yet the electrical conductivity increased by $21 \%$ with the addition of $0.42 \mathrm{wt} \%$ CNT-A. It can also be noted that GT PAN/CNT-A (0.42 wt $\%)$ exhibits a 6\% increase in electrical conductivity at $295 \mathrm{~K}$ as compared to GT PAN/CNT-A(1.0 wt $\%)$. The higher electrical conductivity in GT PAN/CNT-A $(0.42 \mathrm{wt} \%)$ can be attributed to the improved tensile modulus, higher $f_{(002)}$, and larger $L_{(10)}$ and $L_{(002)}$ crystal size of GT PAN/CNT-A $(0.42 \mathrm{wt} \%)$ as compared to GT PAN/CNT-A (1.0 wt\%). 

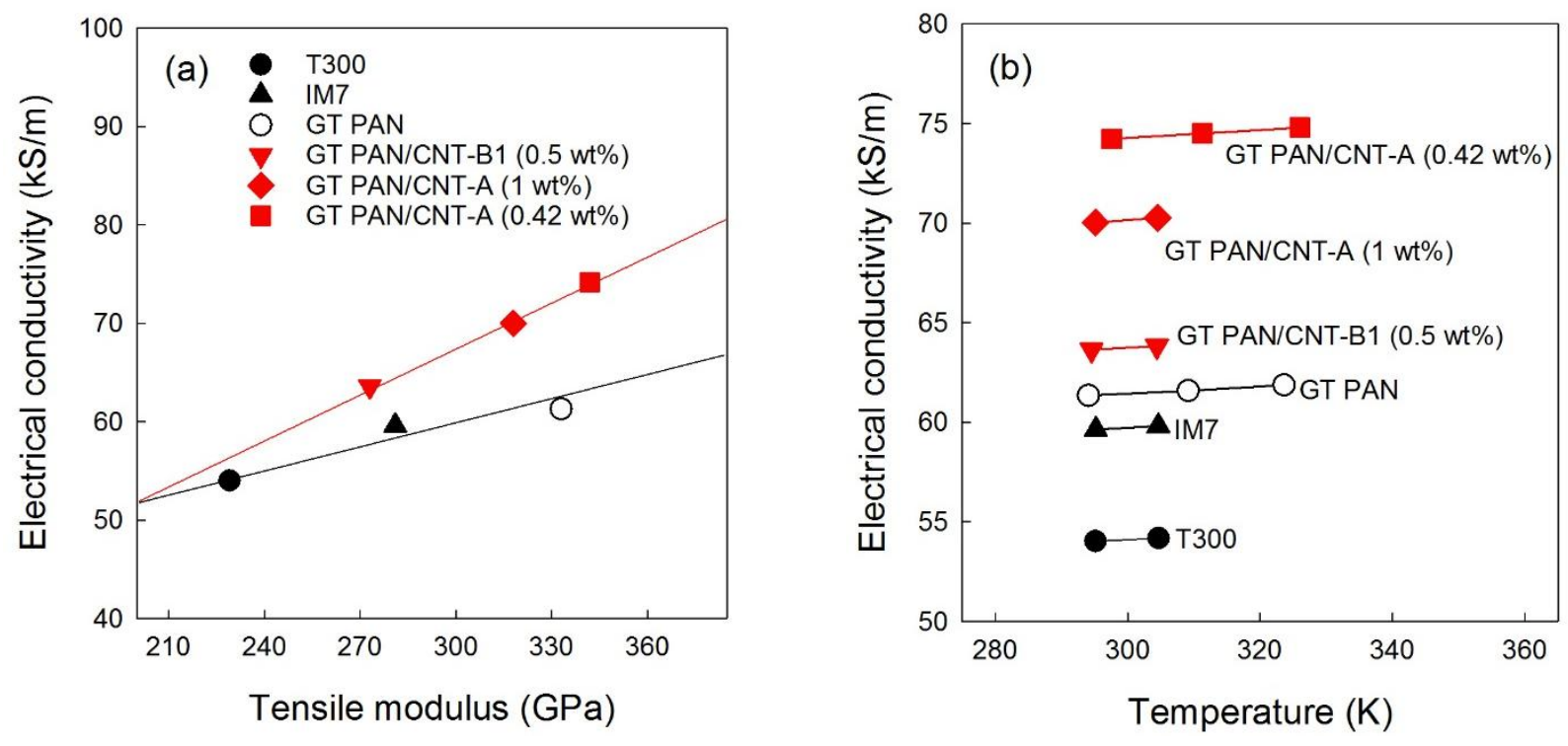

Fig. 5 - Electrical conductivities of various carbon fibers as a function of (a) tensile modulus ( $\mathrm{T}$ $295 \mathrm{~K}$ ) and (b) temperature. Tensile moduli of various carbon fibers are compliance corrected values.

Considering that the GT PAN/CNT-A $(0.42 \mathrm{wt} \%)$ carbon fiber has an estimated $1.4 \mathrm{vol} \%$ of the $\mathrm{HO}$ graphitic region (Table 3), the parallel model (equation 7), predicts an electrical conductivity of $74.5 \mathrm{kS} / \mathrm{m}$.

$$
\sigma_{c}=\sigma_{p} V_{p}+\sigma_{m} V_{m}
$$

where $\sigma_{p}, V_{p}, \sigma_{m}$, and $V_{m}$ are the templated graphitic electrical conductivity and volume fraction, matrix electrical conductivity, and matrix volume fraction, respectively.

The volume fraction of the turbostratic matrix is approximately 0.986 , as determined from the azimuthal scan and $\sigma_{p}$ is which was assumed to be $10^{6} \mathrm{~S} / \mathrm{m}$ and $\sigma_{m}$ is $61.3 \mathrm{kS} / \mathrm{m}$ as measured for the GT PAN carbon fiber. Use of the parallel model to determine the electrical conductivity coupled with the volume fraction determination WAXD results in a $0.3 \%$ error between the measured and predicted electrical conductivity of the GT PAN/CNT-A (0.42 wt $\%)$ carbon fiber. Considering the similar $f_{\text {matrix }}, L_{(002)}, L_{(10)}$, and tensile modulus of the IM7 and the 
GT PAN/CNT-B1 (0.5 wt $\%)$ fibers, the parallel model can be used to predict the electrical conductivity of the composite fiber within $4 \%$ error using the series model. Such a calculation results in a predicted electrical conductivity of $66.2 \mathrm{kS} / \mathrm{m}$ for the GT PAN/CNT-B (0.5 wt $\%)$ carbon fiber where $\sigma_{m}$ is $59.2 \mathrm{kS} / \mathrm{m}$ for IM7, and $V_{m}$ is 0.993 .

\subsection{Mechanical properties of the PAN and PAN/CNT based carbon fibers}

Single filament tensile testing was conducted based on the testing method established for carbon fibers[53], and the results are listed in Table 2. The GT PAN carbon fiber exhibits a 45 and $21 \%$ increase in tensile modulus as compared to T300 and IM7. IM7 is $32 \%$ stronger than the GT PAN carbon fiber and the GT PAN carbon fiber is $17 \%$ stronger than T300, at a $25.4 \mathrm{~mm}$ gauge length. The lower tensile strength of the GT PAN carbon fiber as compared to IM7 can be attributed to its irregular cross-sectional shape (Fig. 6c), surface defects, smaller tow size, and lack of surface treatment. In general, relatively good tensile strength of the GT PAN fiber is a result of gel spinning and processing in the cleanroom. For comparison, the cross-sectional SEM images of the T300 and IM7 carbon fibers are also shown in Fig. 6a and 6b, respectively. The T300 carbon fiber shows a non-circular cross-section, the IM7 fiber cross-section exhibits a circular cross-section. Irregular cross-sectional shapes will lead to the uneven oxygen diffusion during stabilization and result in reduced fiber properties[58]. The GT PAN carbon fiber also has an irregular cross-sectional shape as shown in Fig. 6c, yet does not show the same sheath-core morphology as T300 as observed in Fig. 1. 


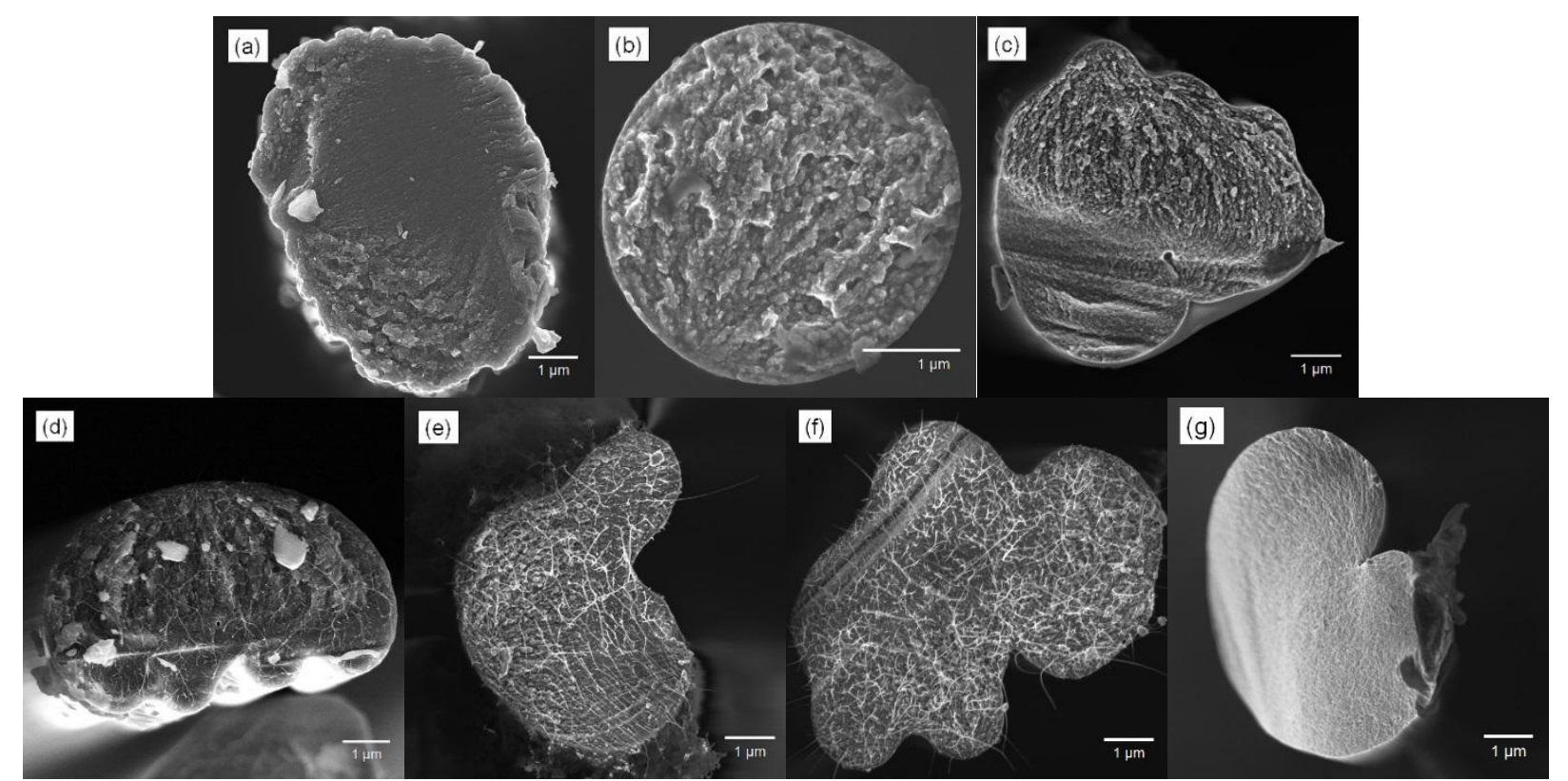

Fig. 6 - SEM cross-sectional images of various carbon fibers: (a) T300, (b) IM7, (c) GT PAN, (d) GT PAN/CNT-A (0.42 wt \%), (e) GT PAN/CNT-B1 (0.5 wt\%), (f) GT PAN/CNT-A (1.0 wt \%), and $(\mathrm{g}) \mathrm{GT}$ PAN/CNT-C $(0.5 \mathrm{wt} \%)$.

GT PAN/CNT based carbon fibers also exhibited irregular cross-sectional shapes, and their tensile strengths were lower than those of the T300, IM7, or the GT PAN carbon fibers (Table 2). Tensile strength will be dependent upon the presence of defects[59], which needs to be minimized or eliminated, and will be aided through improved CNT dispersion within the PAN/CNT based carbon fiber. Another source of defects is the presence of metallic impurities (present in the as-received CNTs), which have been shown to reduce carbon fiber tensile strength[60]. During carbonization, this can create a void structure in the surrounding carbon material[61]. It was also shown in a controlled study that carbonization in the presence of silicon or iron oxide impurity $(\sim 0.1 \mathrm{wt} \%)$, the resulting fracture stress reduced by a factor of $3[62]$. Therefore, removal of catalytic impurities and purification of CNTs appears to have an important role in the processing and properties of PAN/CNT based carbon fiber. It can also be noted that, based on the HR-TEM study (Fig. 3b1), the CNT bundle in the composite carbon fiber can lead 
to the formation of voids which would not be present in the similarly processed PAN based carbon fiber. Fig. 7a shows a schematic description of how the bundled nature of the CNTs could introduce voids into the carbonized fiber. These voids are present in the HR-TEM transverse cross section images of the carbon fiber in Fig. $7 \mathrm{~b}$ and $7 \mathrm{c}$, showing that large voids $(4-5 \mathrm{~nm}$ in transverse direction) are formed. The voids are expected to be created throughout the fiber crosssection due to the non-uniform length of CNTs and bundling of the CNTs. As the CNT bundle takes shape during solution processing and precursor fiber formation due to an imperfect dispersion, regions within the CNT bundle form voids. The voids are the result of either not being accessible by the PAN molecules, or the PAN molecules which can penetrate the once vacant region within the CNT bundle are not able to survive the carbonization process due to an incomplete stabilization reaction by limited oxygen diffusion. In addition, any extraneous metal catalytic impurity within the CNT (about $1-3 \mathrm{wt} \%$ with respect to the CNT weight in the current study) will be detrimental to the production of high strength carbon fiber. These impurities, along with internal voids and surface defects must be eliminated in order to maximize the potential tensile strength of the PAN/CNT based carbon fiber. 
(a) Side View

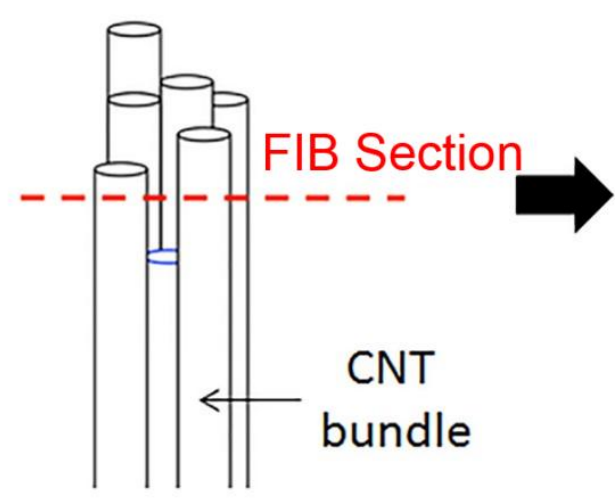

Top View

FIB Section

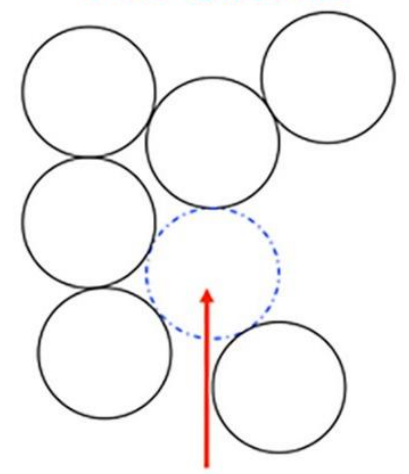

Resulting void region
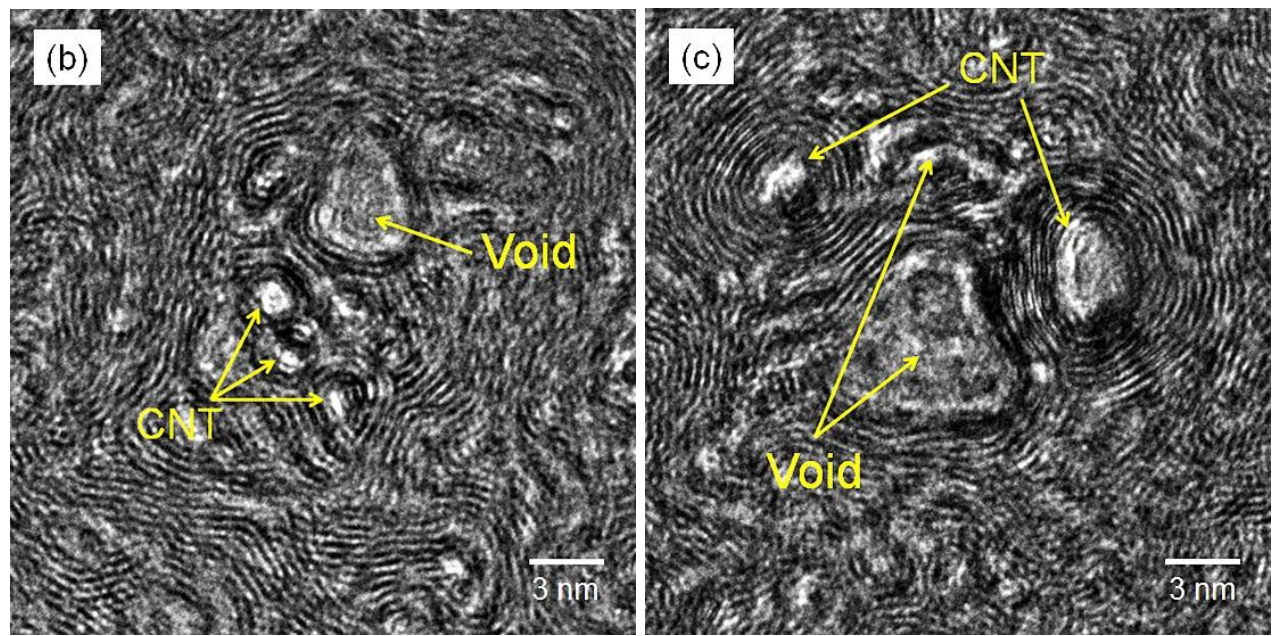

Fig. 7 - (a) Schematic description of CNT bundle, showing that the difference in CNT length can result in voids within the fiber cross-section, HR-TEM transverse cross-section images of (b) GT PAN/CNT-A (0.42 wt \%) and (c) GT PAN/CNT-A (1.0 wt \%), showing the presence of voids.

\section{Conclusions}

Gel spun PAN and PAN/CNT based carbon fibers were produced using a laboratory scale spinning facility and continuous carbonization. HR-TEM study showed that the GT processed PAN and PAN/CNT based carbon fibers had enhanced crystalline perfection as compared to T300 and IM7 fibers. It was also shown that CNTs can provide nucleation sites for graphitic 
carbon structural development. This led to the improvement in thermal and electrical conductivities. Up to $1.0 \mathrm{wt} \% \mathrm{CNT}$ addition in the precursor fiber resulted in a $68 \%$ increase in thermal conductivity as compared to the GT PAN carbon fiber, and a $103 \%$ and $146 \%$ increase over commercially available IM7 and T300 carbon fibers, respectively. Additionally, the GT PAN/CNT based carbon fibers exhibited a $21 \%$ increase in electrical conductivity as compared to the GT PAN carbon fiber, and a $24 \%$ and $37 \%$ increase as compared to IM7 and T300, respectively. However, GT PAN/CNT based carbon fibers showed lower tensile strength than the GT PAN and commercial PAN carbon fibers, which is attributed to the void structure from the CNT bundles and metallic impurities present in the as-received CNTs. Therefore, to obtain high strength and high modulus PAN/CNT based carbon fiber with multi-functionality (high electrical and high thermal conductivities), CNT bundling behavior and metallic impurity content must be minimized.

\section{Acknowledgements:}

The authors acknowledge the financial support by DARPA and the Army Research Office (Grant Number W911NF-10-1-0098). The TEM used in this work is supported by funding from NSF (DMR 0922776). 


\section{References:}

[1] Minus ML, Chae HG, Kumar S. Polyethylene crystallization nucleated by carbon nanotubes under shear. ACS Applied Materials \& Interfaces. 2012;4(1):326-30.

[2] Bhattacharyya AR, Sreekumar TV, Liu T, Kumar S, Ericson LM, Hauge RH, et al. Crystallization and orientation studies in polypropylene/single wall carbon nanotube composite. Polymer. 2003;44(8):2373-7.

[3] Li CY, Li LY, Cai WW, Kodjie SL, Tenneti KK. Nanohybrid shish-kebabs: Periodically functionalized carbon nanotubes. Advanced Materials. 2005;17(9):1198-202.

[4] Anand KA, Agarwal US, Joseph R. Carbon nanotubes induced crystallization of poly(ethylene terephthalate). Polymer. 2006;47(11):3976-80.

[5] Minus ML, Chae HG, Kumar S. Single wall carbon nanotube templated oriented crystallization of poly(vinyl alcohol). Polymer. 2006;47(11):3705-10.

[6] Chae HG, Minus ML, Kumar S. Oriented and exfoliated single wall carbon nanotubes in polyacrylonitrile. Polymer. 2006;47(10):3494-504.

[7] Zhang Y, Song K, Meng J, Minus ML. Tailoring polyacrylonitrile interfacial morphological structure by crystallization in the presence of single-wall carbon nanotubes. ACS Applied Materials \& Interfaces. 2013;5(3):807-14.

[8] Minus ML, Kumar S. The processing, properties, and structure of carbon fibers. Journal of Materials. 2005;57(2):52-8.

[9] Liu Y, Kumar S. Recent progress in fabrication, structure, and properties of carbon fibers. Polymer Reviews. 2012;52(3-4):234-58.

[10] Edie DD. The effect of processing on the structure and properties of carbon fibers. Carbon. 1998;36(4):345-62.

[11] Qiu L, Zheng XH, Zhu J, Su GP, Tang DW. The effect of grain size on the lattice thermal conductivity of an individual polyacrylonitrile-based carbon fiber. Carbon. 2013;51(0):265-73. [12] Oya N, Johnson DJ. Longitudinal compressive behaviour and microstructure of PANbased carbon fibres. Carbon. 2001;39(5):635-45.

[13] Andrews R, Jacques D, Rao AM, Rantell T, Derbyshire F, Chen Y, et al. Nanotube composite carbon fibers. Applied Physics Letters. 1999;75(9):1329-31.

[14] Chae HG, Minus ML, Rasheed A, Kumar S. Stabilization and carbonization of gel spun polyacrylonitrile/single wall carbon nanotube composite fibers. Polymer. 2007;48(13):3781-9.

[15] Chae HG, Choi YH, Minus ML, Kumar S. Carbon nanotube reinforced small diameter polyacrylonitrile based carbon fiber. Composites Science and Technology. 2009;69(3-4):406-13. [16] Liu YD, Chae HG, Kumar S. Gel-spun carbon nanotubes/polyacrylonitrile composite fibers. Part III: Effect of stabilization conditions on carbon fiber properties. Carbon. 2011;49(13):4487-96.

[17] Sahin K, Fasanella NA, Chasiotis I, Lyons KM, Newcomb BA, Kamath MG, et al. High strength micron size carbon fibers from polyacrylonitrile-carbon nanotube precursors. Carbon. 2014;77:442-53.

[18] Prilutsky S, Zussman E, Cohen Y. Carbonization of electrospun poly(acrylonitrile) nanofibers containing multiwalled carbon nanotubes observed by transmission electron microscope with in situ heating. Journal of Polymer Science Part B-Polymer Physics. 2010;48(20):2121-8. 
[19] Papkov D, Beese AM, Goponenko A, Zou Y, Naraghi M, Espinosa HD, et al. Extraordinary improvement of the graphitic structure of continuous carbon nanofibers templated with double wall carbon nanotubes. ACS Nano. 2013;7(1):126-42.

[20] Naito K, Yang J-M, Xu Y, Kagawa Y. Enhancing the thermal conductivity of polyacrylonitrile- and pitch-based carbon fibers by grafting carbon nanotubes on them. Carbon. 2010;48(6):1849-57.

[21] Nysten B, Issi JP, Barton R, Boyington DR, Lavin JG. Determination of lattice defects in carbon fibers by means of thermal-conductivity measurements. Physical Review B. 1991;44(5):2142-8.

[22] Zhang X, Fujiwara S, Fujii M. Measurements of thermal conductivity and electrical conductivity of a single carbon fiber. International Journal of Thermophysics. 2000;21(4):965-80.

[23] Maruyama S. A molecular dynamics simulation of heat conduction in finite length SWNTs. Physica B-Condensed Matter. 2002;323(1-4):193-5.

[24] Zhang G, Li BW. Thermal conductivity of nanotubes revisited: Effects of chirality, isotope impurity, tube length, and temperature. Journal of Chemical Physics. 2005;123(11).

[25] Cao JX, Yan XH, Xiao Y, Ding JW. Thermal conductivity of zigzag single-walled carbon nanotubes: Role of the umklapp process. Physical Review B. 2004;69(7):073407.

[26] Fujii M, Zhang X, Xie HQ, Ago H, Takahashi K, Ikuta T, et al. Measuring the thermal conductivity of a single carbon nanotube. Physical Review Letters. 2005;95(6):065502.

[27] Shenogin S, Bodapati A, Xue L, Ozisik R, Keblinski P. Effect of chemical functionalization on thermal transport of carbon nanotube composites. Applied Physics Letters. 2004;85(12):2229-31.

[28] Yu CH, Shi L, Yao Z, Li DY, Majumdar A. Thermal conductance and thermopower of an individual single-wall carbon nanotube. Nano Letters. 2005;5(9):1842-6.

[29] Mingo N, Broido DA. Carbon nanotube ballistic thermal conductance and its limits. Physical Review Letters. 2005;95(9):096105.

[30] Cao JX, Yan XH, Xiao Y, Tang Y, Ding JW. Exact study of lattice dynamics of singlewalled carbon nanotubes. Physical Review B. 2003;67(4):045413.

[31] Kim P, Shi L, Majumdar A, McEuen PL. Thermal transport measurements of individual multiwalled nanotubes. Physical Review Letters. 2001;87(21):215502.

[32] Kelly BT. Physics of graphite: London ; Englewood, N.J. : Applied Science, c1981.; 1981.

[33] Yi W, Lu L, Zhang DL, Pan ZW, Xie SS. Linear specific heat of carbon nanotubes. Physical Review B. 1999;59(14):R9015-R8.

[34] Hone J, Llaguno MC, Nemes NM, Johnson AT, Fischer JE, Walters DA, et al. Electrical and thermal transport properties of magnetically aligned single wall carbon nanotube films. Applied Physics Letters. 2000;77(5):666-8.

[35] Pop E, Mann D, Wang Q, Goodson KE, Dai HJ. Thermal conductance of an individual single-wall carbon nanotube above room temperature. Nano Letters. 2006;6(1):96-100.

[36] Zhong H, Lukes JR. Interfacial thermal resistance between carbon nanotubes: Molecular dynamics simulations and analytical thermal modeling. Physical Review B. 2006;74(12):125403. [37] Gulotty R, Castellino M, Jagdale P, Tagliaferro A, Balandin AA. Effects of functionalization on thermal properties of single-wall and multi-wall carbon nanotube-polymer nanocomposites. ACS Nano. 2013;7(6):5114-21. 
[38] Yu A, Itkis ME, Bekyarova E, Haddon RC. Effect of single-walled carbon nanotube purity on the thermal conductivity of carbon nanotube-based composites. Applied Physics Letters. 2006;89(13):133102.

[39] Hong W-T, Tai N-H. Investigations on the thermal conductivity of composites reinforced with carbon nanotubes. Diamond and Related Materials. 2008;17(7-10):1577-81.

[40] Song YS, Youn JR. Influence of dispersion states of carbon nanotubes on physical properties of epoxy nanocomposites. Carbon. 2005;43(7):1378-85.

[41] Stauffer D, Aharony A. Introduction to percolation theory: London ; Washington, DC : Taylor \& Francis, 1992. 2nd ed.; 1992.

[42] Du FM, Fischer JE, Winey KI. Effect of nanotube alignment on percolation conductivity in carbon nanotube/polymer composites. Physical Review B. 2005;72(12):121404.

[43] Straat M, Toll S, Boldizar A, Rigdahl M, Hagstrom B. Melt spinning of conducting polymeric composites containing carbonaceous fillers. Journal of Applied Polymer Science. 2011;119(6):3264-72.

[44] Potschke P, Brunig H, Janke A, Fischer D, Jehnichen D. Orientation of multiwalled carbon nanotubes in composites with polycarbonate by melt spinning. Polymer. 2005;46(23):10355-63.

[45] Haggenmueller R, Gommans HH, Rinzler AG, Fischer JE, Winey KI. Aligned singlewall carbon nanotubes in composites by melt processing methods. Chemical Physics Letters. 2000;330(3-4):219-25.

[46] Chien A-T, Gulgunje PV, Chae HG, Joshi AS, Moon J, Feng B, et al. Functional polymer-polymer/carbon nanotube bi-component fibers. Polymer. 2013;54(22):6210-7.

[47] Newcomb BA, Chae HG, Gulgunje PV, Gupta K, Liu Y, Tsentalovich DE, et al. Stress transfer in polyacrylonitrile/carbon nanotube composite fibers. Polymer. 2014;55(11):2734-43. [48] Chae HG, Newcomb BA, Gulgunje PV, Liu Y, Gupta K, Kamath MG, et al. High strength and high modulus carbon fibers. Submitted.

[49] Moon J, Weaver K, Feng B, Chae HG, Kumar S, Baek J-B, et al. Thermal conductivity measurement of individual poly(ether ketone)/carbon nanotube fibers using a steady-state dc thermal bridge method. Review of Scientific Instruments. 2012;83(1):016103.

[50] Zhou GS, Liu YQ, He LL, Guo QG, Ye HQ. Microstructure difference between core and skin of T700 carbon fibers in heat-treated carbon/carbon composites. Carbon. 2011;49(9):288392.

[51] Liu XF, Zhu CZ, Guo J, Liu QL, Dong HX, Gu YZ, et al. Nanoscale dynamic mechanical imaging of the skin-core difference: From PAN precursors to carbon fibers. Materials Letters. 2014;128:417-20.

[52] Heremans J, Rahim I, Dresselhaus MS. Thermal conductivity and Raman spectra of carbon fibers. Physical Review B. 1985;32(10):6742-7.

[53] Lyons KM, Newcomb BA, McDonald KJ, Chae HG, Kumar S. Development of single filament testing procedure for polyacrylonitrile precursor and polyacrylonitrile-based carbon fibers. Journal of Composite Materials. 2014;0(0):1-10.

[54] Ho CY, Powell RW, Liley PE. Thermal Conductivity of the Elements. Journal of Physical and Chemical Reference Data. 1972;1(2):279-421.

[55] Bacon GE. A method for determining the degree of orientation of graphite. Journal of Applied Chemistry. 1956;6(11):477-81.

[56] Fischbach DB. Preferred Orientation Parameters for Pyrolytic Carbons. Journal of Applied Physics. 1966;37(5):2202-3. 
[57] Han Z, Fina A. Thermal conductivity of carbon nanotubes and their polymer nanocomposites: A review. Progress in Polymer Science. 2011;36(7):914-44.

[58] Warner SB, Peebles LH, Uhlmann DR. Oxidative stabilization of acrylic fibers. Part 1. Oxygen uptake and general model. Journal of Materials Science. 1979;14(3):556-64.

[59] Chae HG, Kumar S. Materials science - Making strong fibers. Science. 2008;319(5865):908-9.

[60] Moreton R, Watt W. Tensile strengths of carbon fibers. Nature. 1974;247(5440):360-1. [61] Sharp JV, Burney SG. Proceedings of the International Conference on Carbon Fibers, Their Composites, and Applications. London: The Plastics Institute; p. 10.

[62] Reynolds WN, Moreton R. Some factors affecting the strengths of carbon fibers. Philosophical Transactions of the Royal Society a-Mathematical Physical and Engineering Sciences. 1980;294(1411):451-61. 